\title{
Produção de massa seca, relação folha/colmo e alguns índices de crescimento do Brachiaria brizantha cv. Xaraés cultivado com a combinação de doses de nitrogênio e potássio
}

\author{
Rosane Cláudia Rodrigues ${ }^{1^{\star}}$, Gerson Barreto Mourão ${ }^{2}$, Kathery Brennecke ${ }^{3}$, Pedro Henrique \\ de Cerqueira Luz $^{3}$, Valdo Rodrigues Herling ${ }^{3}$
}

\footnotetext{
${ }_{1}$ Programa de Pós-graduação em Qualidade e Produtividade Animal do Departamento de Zootecnia da FZEA/USP.

2 Departamento de Ciências Exatas - ESALQ/USP, Piracicaba-SP.

${ }^{3}$ Departamento de Zootecnia - FZEA/USP, Pirassununga-SP.
}

\begin{abstract}
RESUMO - Objetivou-se avaliar a produção de massa seca das folhas, a relação folha/colmo e alguns índices de crescimento do capim-xaraés submetido a doses de nitrogênio $(\mathrm{N})$ e potássio $(\mathrm{K})$. O experimento foi conduzido em casa-de-vegetação no período de novembro/2004 a fevereiro/2005. Adotou-se esquema fatorial $4 \times 3$, perfazendo 12 combinações, as quais foram distribuídas em delineamento experimental inteiramente casualizado, com quatro repetições, perfazendo um total 48 unidades experimentais. Foram utilizadas quatro doses de $\mathrm{N}\left(0,75,150\right.$ e $\left.225 \mathrm{mg} \mathrm{dm}^{-3}\right)$ e três doses de $\mathrm{K}\left(0,50\right.$ e $\left.100 \mathrm{mg} \mathrm{dm}^{-3}\right)$. Verificou-se efeito das doses de $\mathrm{N}$ na produção de massa seca das folhas e na produção de massa seca total, em todos os cortes, com maior produção nas doses mais elevadas de $\mathrm{N}$, ao passo que o K influenciou essas variáveis apenas no segundo corte. A relação folha/ colmo, a RAF, a AFE e a RPF somente foram significativas no terceiro corte da planta. Os efeitos das doses de foram decrescentes sobre essas variáveis, enquanto as doses de $\mathrm{K}$ agiram de modo antagônico às doses de $\mathrm{N}$ sobre a RAF e AFE.
\end{abstract}

Palavras-chave: área foliar específica, nutrição mineral, razão de área foliar, razão de peso foliar

\section{Dry matter production, leaf/stem ratio and growth indexes of palisade grass (Brachiaria brizantha cv. Xaraés), cultivated with different rate combinations of nitrogen and potassium}

\begin{abstract}
This work aimed to evaluate dry matter production, leaf/stem ratio and growth indexes of palisade grass cv. Xaraés grown under increasing nitrogen and potassium rates. The experiment was carried out in a greenhouse from November, 2004 until February, 2005. The experimental treatments consisted of a $4 \times 3$ factorial arrangement between nitrogen and potassium rates respectively. Nitrogen rates were $0,75,150$, and $225 \mathrm{mg} \mathrm{dm}^{-3}$, whereas potassium rates were $0 ; 50$ and $100 \mathrm{mg} \mathrm{dm}^{-3}$. The experiment design was completely randomized with four replications. It was verified a positive $\mathrm{N}$ fertilization effect both on leaf dry matter yield and total dry matter yield. Potassium influenced these same response variables only at the second harvest. The leaf/stem ratio, leaf area ratio (LAR), specific leaf area (SLA) and, leaf weight ratio (LWR) were affected by treatments only at the third harvest. Increasing $\mathrm{N}$ rates reduced these response variables (L/S, LAR, SLA, LWR) while potassium rates behaved in an antagonistic way on LAR and SLA.
\end{abstract}

Key Words: leaf area ratio, leaf weight ratio, mineral nutrition, specific leaf area

\section{Introdução}

As folhas constituem-se em órgãos das plantas responsáveis pela fotossíntese, além de serem a principal fonte de nutrientes para os ruminantes em sistemas de pastejo. Evidencia-se, dessa maneira, a necessidade de se investigarem os modelos morfofisiológicos que se tornam indispensáveis para a definição de estratégias de manejo de pastos.
As porções verde da planta são as mais nutritivas da dieta e consumidas preferencialmente pelos animais (Wilson \& t'Mannetje, 1978). Segundo esses autores, alta relação folha/colmo representa forragem com elevados teor de proteína, digestibilidade e consumo, além de conferir à gramínea melhor adaptação ao pastejo ou tolerância ao corte. Em condições de pastejo, o consumo é influenciado pela disponibilidade de forragem e pela estrutura da vegetação como a relação folha/colmo.

Este artigo foi recebido em 20/10/2006 e aprovado em 11/9/2007. 
Existem variações entre as espécies de gramíneas com relação ao peso dessas frações (folha/colmo), importantes do ponto de vista do valor nutritivo e do manejo das espécies forrageiras (Pinto et al., 1994). Por outro lado, a análise de crescimento possibilita identificar as características das plantas asssociadas à adaptação e potencial de produção em condições favoráveis, além de ser indicativo dos efeitos de ambiente nas diferentes espécies.

Segundo Hunt (1990), entre os principais índices de crescimento, têm-se as taxas de crescimento relativo e absoluto e razões simples como a razão de área foliar (RAF), a razão de peso foliar (RPF) e a área foliar específica (AFE).

De acordo com Benicasa (1988), a RAF é um componente morfofisiológico do crescimento que expressa a razão entre área foliar (área responsável pela interceptação de energia luminosa e $\mathrm{CO}_{2}$ ) e a massa seca total (resultado da fotossíntese), que representa a área foliar sendo usada pela planta para produzir unidade de massa seca. A RPF um componente físiológico - é a razão entre a massa de folhas e a massa da parte aérea da planta (expressa a fração de massa seca não-exportada das folhas para o restante da planta). A AFE - um componente morfológico e anatômico da RAF - relaciona a superfície com a massa seca da própria folha e seu inverso expressa diretamente a espessura da folha.

Segundo Hunt (1990), essas características variam em decorrência de alterações nos níveis de luz, tempera tura, umidade e disponibilidade de nutrientes, enfatizando, dessa forma, a necessidade de se conhecerem as respostas morfológicas das espécies forrageiras ao ambiente, para o entendimento de adaptações das mesmas às práticas de manejo a serem adotadas. Por se tratar de um cultivar relativamente novo, existem poucas informações relativas a sua exigência nutricional, o que justifica a realização de estudos com a finalidade de se obterem dados referentes ao seu comportamento morfológico e produtivo.

Objetivou-se, com este estudo, avaliar a produção de massa seca da parte aérea, a relação folha/colmo e algumas características morfológicas (RAF, RPF e AFE) do Brachiaria brizanthacv.Xaraés cultivado com a combinação de doses de nitrogênio $(\mathrm{N})$ e potássio $(\mathrm{K})$.

\section{Material e Métodos}

O experimento foi conduzido em casa de vegetação, pertencente ao Departamento de Zootecnia da Faculdade de Zootecnia e Engenharia de Alimento - FZEA/USP. A posição geográfica é $21^{\circ} 59^{\prime}$ de latitude sul e $47^{\circ} 26^{\prime}$ de longitude oeste, com altitude de $634 \mathrm{~m}$, sendo o clima subtropical do tipo Cwa com inverno seco e verão quente e chuvoso (Oliveira \& Prado, 1984). A espécie utilizada foi o Brachiaria brizantha (Hochst ex A. Rich.) Stapf. cv. Xaraés, cultivada no período de novembro/2004 a fevereiro/2005.

Foi utilizado um esquema fatorial $4 \times 3$, envolvendo quatro doses de $\mathrm{N}\left(0,75,150\right.$ e $\left.225 \mathrm{mg} \mathrm{dm}^{-3}\right)$ e três doses de $\mathrm{K}\left(0,50 \mathrm{e} 100 \mathrm{mg} \mathrm{dm}^{3}\right)$, que corresponde a $0,150,300 \mathrm{e}$ $450 \mathrm{~kg} \mathrm{ha}^{-1}$ de $\mathrm{N}$ e a 0,100 e $200 \mathrm{~kg} \mathrm{ha}^{-1}$ de $\mathrm{K}$, perfazendo um total de 12 combinações. O delineamento experimental utilizado foi o inteiramente casualizado, com arranjo fatorial $4 \times 3$. Cada tratamento teve quatro repetições, totalizando 48 unidades experimentais.

Do local onde foi amostrada e coletada terra, na profundidade de 0 a $20 \mathrm{~cm}$ para análise química (Tabela 1) e enchimento dos vasos, o solo foi classificado como Latossolo Vermelho Amarelo, fase arenosa (EMBRAPA, 1999). Depois de secas, homogeneizadas, peneiradas e pesadas, amostras deste solo foram colocadas em vasos de cerâmica com capacidade para $2,9 \mathrm{~kg}$.

A semeadura foi realizada utilizando-se 30 sementes por vaso. O desbaste aconteceu 15 dias após a emergência das plantas (10/11/2004), deixando cinco plantas/vaso e, em seguida, foram aplicadas as respectivas doses de $\mathrm{N}$ e $\mathrm{K}$ na forma de uréia e $\mathrm{KCl}$. O 10 corte foi realizado 60 dias após o plantio e 41 dias após o corte de uniformização (20/12/2004); o 2으, 20 dias após o primeiro (13/1/2005); e o 3 o, 22 dias após o segundo corte $(2 / 2 / 2005)$, de modo que $\mathrm{o}$ intervalo de um corte e outro foi denominado $1 \underline{\mathrm{o}}, 2 \underline{\mathrm{o}} \mathrm{e}$ 3o crescimentos.

Após a emergência das plântulas, foi efetuado o primeiro desbaste, seguido periodicamente até permanecerem cinco plantas uniformes por vaso. Os cortes foram efetuados à altura de $10 \mathrm{~cm}$ do colo das plantas, coletando-se a parte aérea e dividindo-a em folhas e colmos mais bainhas. Esse material foi seco em estufa de circulação

Tabela 1 - Características químicas do solo utilizado no experimento

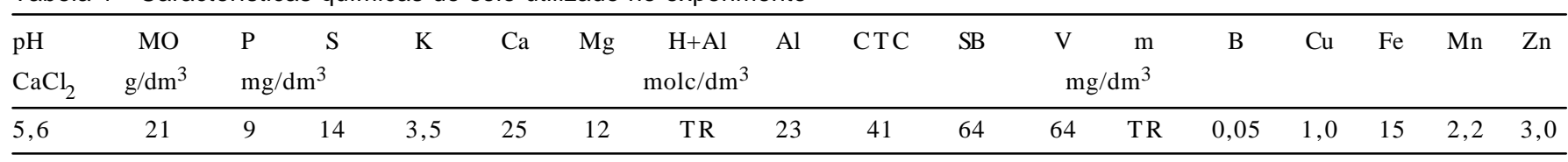


forçada a $65^{\circ} \mathrm{C}$, por 72 horas, para obtenção da massa seca (MS). Com os dados de MS das frações folha:colmo, calcularam-se: a relação folha/colmo; a MS da parte aérea; a RAF, pela divisão da área foliar pela massa seca total; a AFE, pela divisão da área foliar pela MS das folhas; e a RPF, pela divisão da MS das folhas pela MS de toda a planta.

Os valores de massa seca das folhas e relação folha/ colmo e os índices de crescimento foram submetidos à análise de variância e, nos casos de significância $(\mathrm{P}<0,05)$, procedeu-se ao estudo de regressão. Empregou-se o procedimento estatístico "Statistical Analysis System" (SAS, 1996).

\section{Resultados e Discussão}

Com o estudo de regressão, verificou-se efeito $(\mathrm{P}=0,0001)$ para as doses de $\mathrm{N}$ em todos os cortes na produção de massa seca (Figura 1). As respostas às doses de $\mathrm{N}$ foram quadráticas $\left(\mathrm{PMS}_{1} \underline{\mathrm{o}}_{\text {corte }}=0,17+0,0298 \mathrm{~N}-\right.$ $0,00009 \mathrm{~N}^{2}, \mathrm{R}^{2}=0,97 ; \mathrm{PMS}_{2}{ }_{\text {corte }}=0,684+0,0324 \mathrm{~N}-$ $0,00009 \mathrm{~N}^{2}, \mathrm{R}^{2}=0,99$ e $\mathrm{PMS}_{3} \underline{\mathrm{o}}_{\text {corte }} \mathrm{Y3}=0,5232+0,0247 \mathrm{~N}-$ $\left.0,00007 \mathrm{~N}^{2}, \mathrm{R}^{2}=0,99\right)$. Derivando-se as equações, foram encontrados valores de máxima produção de massa seca nas doses de 166,180 e $176 \mathrm{mg} \mathrm{dm}^{-3}$, para o $1 \stackrel{\mathrm{o}}{ }, 2 \underline{\mathrm{o}}$ e $3 \underline{\mathrm{o}}$ cortes, respectivamente.

As doses de $\mathrm{K}$ influenciaram $(\mathrm{P}=0,047)$ a produção de massa seca apenas no $2 \underline{o}$ corte, sendo a resposta de comportamento quadrático (Figura 2). A derivada da equação indicou que a máxima produção foi encontrada com a dose $61 \mathrm{mg} \mathrm{dm}^{-3}$ de $\mathrm{K}$.

Para a produção de MS das folhas, o comportamento observado foi semelhante ao da produção de MS total.

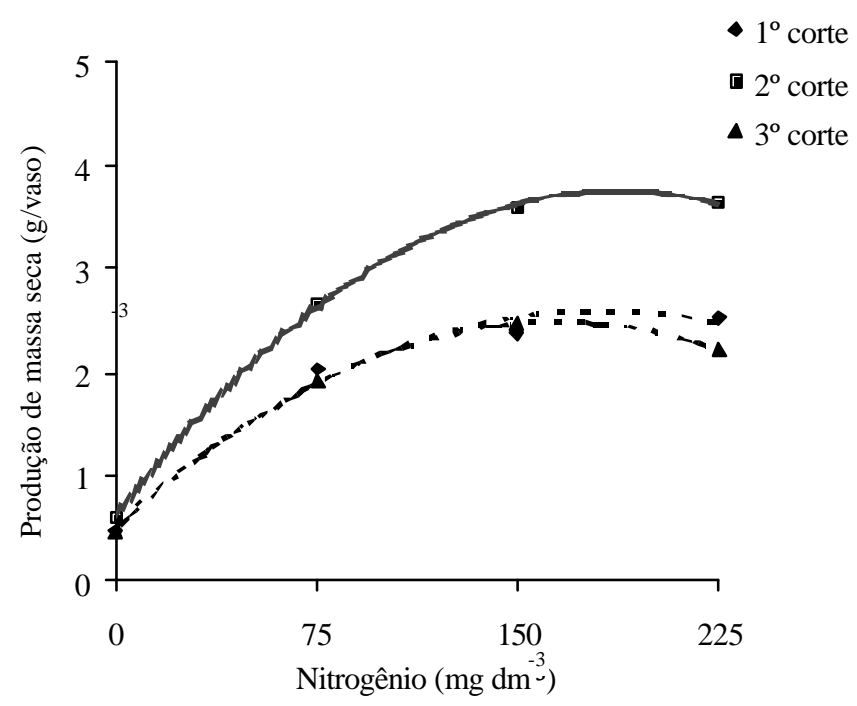

Figura 1 - Produção de massa seca (g/vaso) em função das doses de nitrogênio $\left(\mathrm{mg} \mathrm{dm}^{-3}\right)$, nos três cortes.
Houve efeito $(\mathrm{P}=0,0001)$ para as doses de $\mathrm{N}$ em todos os cortes (Figura 3). Em todos os casos, as respostas às doses de $\mathrm{N}$ foram quadráticas $\left(\mathrm{PMSF}_{1} \underline{\mathrm{o}}_{\text {corte }}=0,1653+0,0283 \mathrm{~N}-\right.$ $0,00008 \mathrm{~N}^{2}, \mathrm{R}^{2}=0,97 ; \mathrm{PMSF}_{2} \underline{\mathrm{o}}_{\text {corte }}=0,5732+0,0316 \mathrm{~N}-$ $0,00009 \mathrm{~N}^{2}, \mathrm{R}^{2}=0,99$ e PMSF${ }_{3} \underline{\mathrm{o}}_{\text {corte }}=0,5224+0,0202 \mathrm{~N}-$ $\left.0,00006 \mathrm{~N}^{2}, \mathrm{R}^{2}=0,99\right)$. Após a derivada das equações, obtiveram-se produções de massa seca de folhas (PMSF) máximas nas doses de 177,176 e $168 \mathrm{mg} \mathrm{dm}^{-3}$, para o $1 \underline{\mathrm{o}}, 2 \underline{\mathrm{o}}$ e $3 \stackrel{\mathrm{o}}{ }$, respectivamente.

As doses de $\mathrm{K}$ influenciaram $(\mathrm{P}=0,057)$ a produção de massa seca das folhas, apenas no segundo corte. Assim como para as doses de $\mathrm{N}$, a resposta para as doses de $\mathrm{K}$ foi quadrática (Figura 4). A derivada da equação indicou que a máxima produção de massa seca de folhas foi encontrada mediante a dose de $60 \mathrm{mg} \mathrm{dm}^{-3} \mathrm{de} \mathrm{K}$.

No primeiro crescimento desse cultivar, observou-se que a produção de massa seca foi composta praticamente de folhas, devido ao estádio inicial de desenvolvimento das plantas, o que pode justificar a ausência de significância para a relação folha/colmo nesse período.

O comportamento quadrático das doses de $\mathrm{N}$ nos três cortes sobre a produção de massa seca sugere que o intervalo de cortes adotado foi suficiente para que as plantas atingissem sua máxima produção, uma vez que, por ocasião da realização do $1 \underline{0}$ corte, as plantas apresentavam tamanho uniforme em cada unidade experimental. Os resultados para esse parâmetro foram semelhantes ao obtido por Monteiro et al. (1995), que trabalharam com o capim-braquiarão em solução nutritiva com subtração de macronutrientes e constataram que os tratamentos testemunha, - $\mathrm{N}$ e -P foram os que mais limitaram o desenvolvimento das plantas e, conseqüentemente, a produção

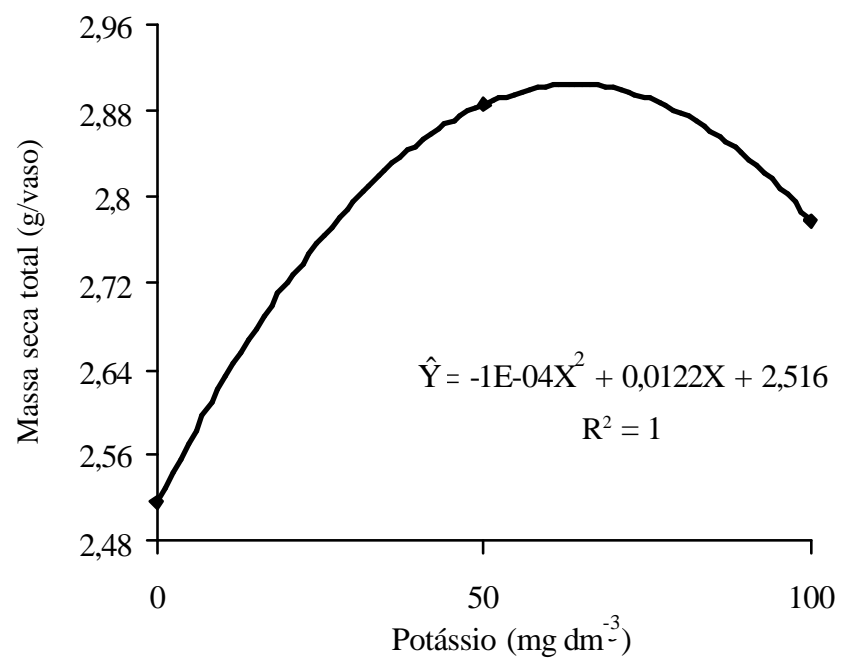

Figura 2 - Produção de massa seca ( $\mathrm{g} / \mathrm{vaso})$ em função das doses de potássio $\left(\mathrm{mg} \mathrm{dm}^{-3}\right)$, no 20 o corte. 


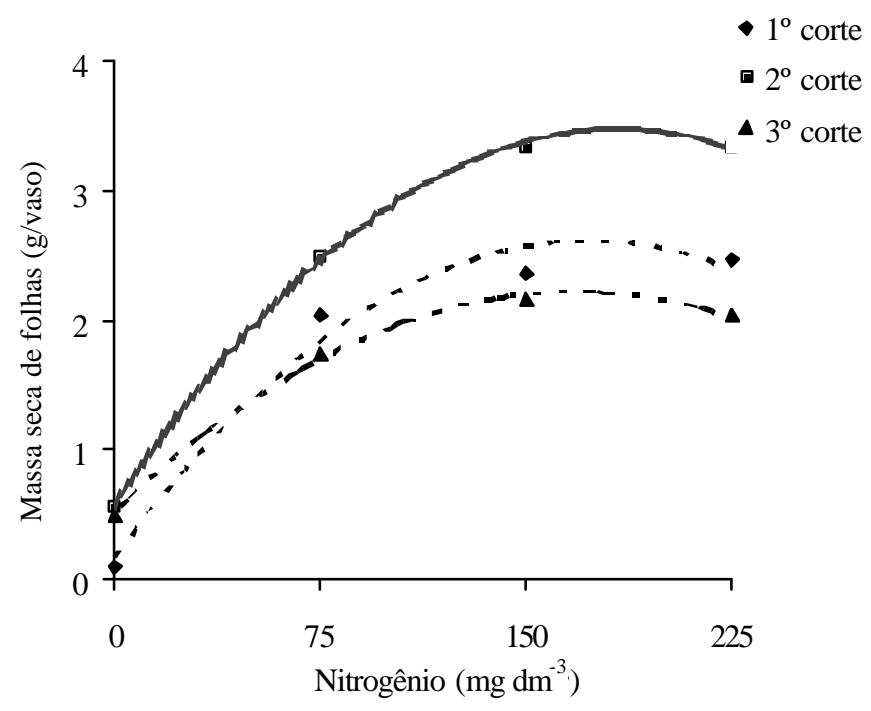

Figura 3 - Produção de massa seca das folhas (g/vaso) em função das doses de nitrogênio $\left(\mathrm{mg} \mathrm{dm}^{-3}\right)$, nos três cortes.

de massa seca, tanto da parte aérea como das raízes, o que também teve reflexo no número de perfilhos e na altura das plantas.

A relação folha/colmo foi significativa apenas no 3o corte. Houve efeito $(\mathrm{P}=0,0044)$ da interação $\mathrm{N} \times \mathrm{K}$ (Figura 5). Pelo estudo de regressão notou-se que a interação foi apenas paras as doses 50 e $100 \mathrm{mg} \mathrm{dm}^{-3} \mathrm{de}$ $\mathrm{K}$ dentro das doses de $\mathrm{N}$, sendo as respostas quadráticas. Observa-se que, nas maiores doses de $\mathrm{N}$, a relação folha/ colmo diminuiu, devido ao maior crescimento das plantas e ao processo de alongamento dos colmos. Ressalta-se que a relação encontrada neste estudo foi superior à relação crítica (1:1), relatado por (Pinto et al., 1994).

De acordo com Sbrissia \& Da Silva (2001), a relação folha/colmo apresenta relevância variada de acordo com a espécie forrageira, sendo menor em espécies de colmo tenro e de menor lignificação. Essa variável pode ser utilizada como índice de valor nutritivo da forragem, pois, assim como a altura do pasto e disponibilidade de massa seca, facilita a preensão de forragem pelo animal e, dessa forma o seu comportamento durante o pastejo (Alden \& Whitaker, 1970).

Em gramíneas de hábito de crescimento ereto, como esse cultivar, o alongamento do colmo incrementa a produção forrageira, porém interfere na estrutura do pasto, comprometendo a eficiência de pastejo em decorrência do decréscimo na relação folha/colmo, que, segundo Euclides et al. (2000), guarda relação direta com o desempenho dos animais em pastejo. De qualquer maneira, os efeitos negativos observados na relação folha/colmo em função do

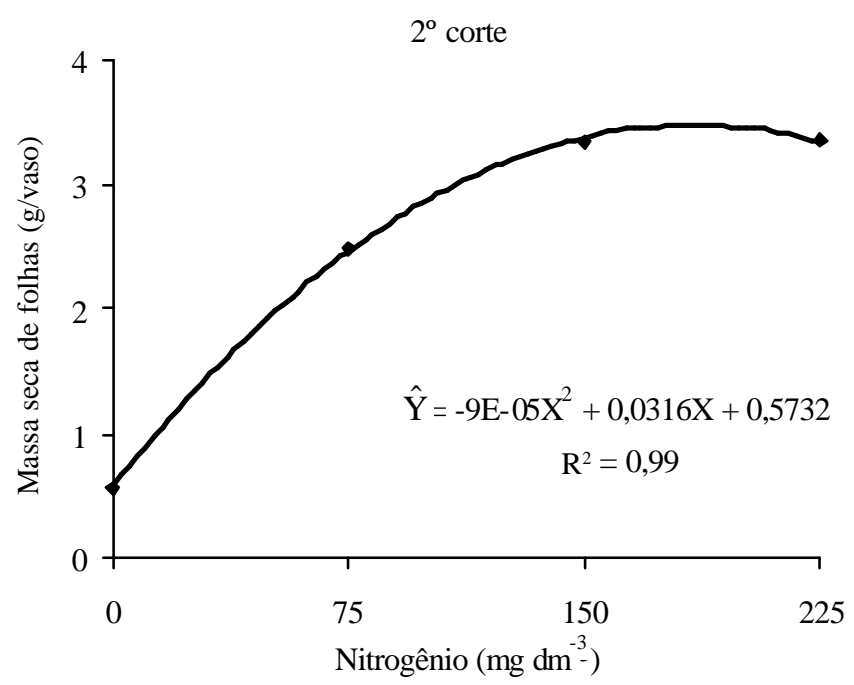

Figura 4 - Produção de massa seca das folhas ( $g / v a s o)$ em função das doses de potássio $\left(\mathrm{mg} \mathrm{dm}^{-3}\right)$, no $2{ }^{\circ}$ corte.

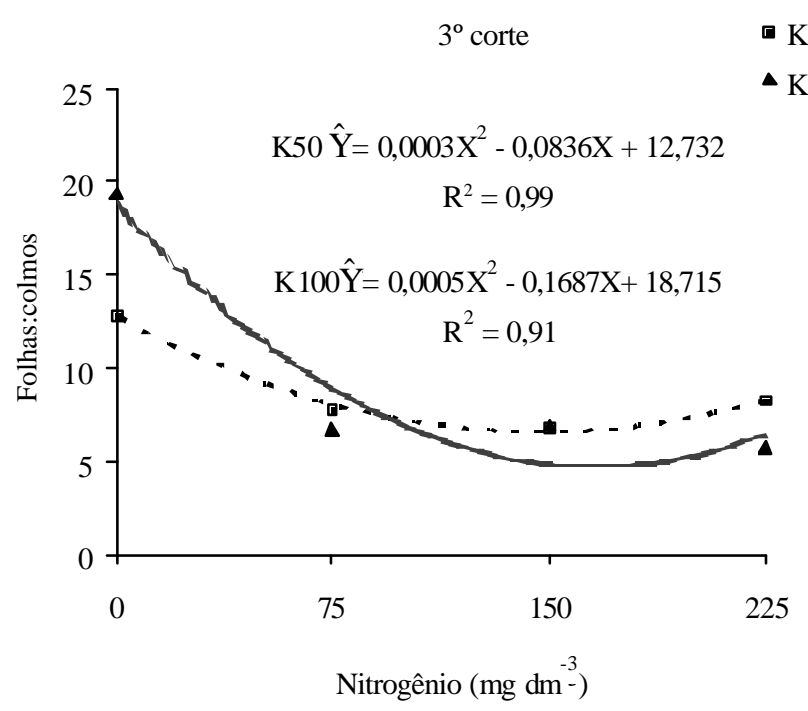

Figura 5 - Relação folha/colmo em função das doses de nitrogênio dentro de doses potássio $\left(\mathrm{mg} \mathrm{dm}^{-3}\right)$, no 3 o corte.

aumento das doses de $\mathrm{N}$ podem ser compensados parcialmente ou totalmente pelo benefício do aumento em produção de fitomassa.

A razão de área foliar (RAF) foi significativa apenas no $3 \underline{o}$ corte. Houve efeito $(\mathrm{P}=0,0057)$ das doses de $\mathrm{N}$ e K $(\mathrm{P}=0,0097)$. A análise de regressão indicou que o comportamento das doses de $\mathrm{N}$ foi linear e decrescente, enquanto a resposta às doses de $\mathrm{K}$ foi linear crescente (Figura 6).

A razão de peso foliar (RPF) foi significativa no $\mathfrak{l}$ $(\mathrm{P}=0,0001)$ e $3 \underline{\mathrm{o}}(0,0193)$ cortes. Pelo estudo de regres$\mathrm{s}$ ão verificou-se que a resposta às doses de $\mathrm{N}$ foi linear nas 

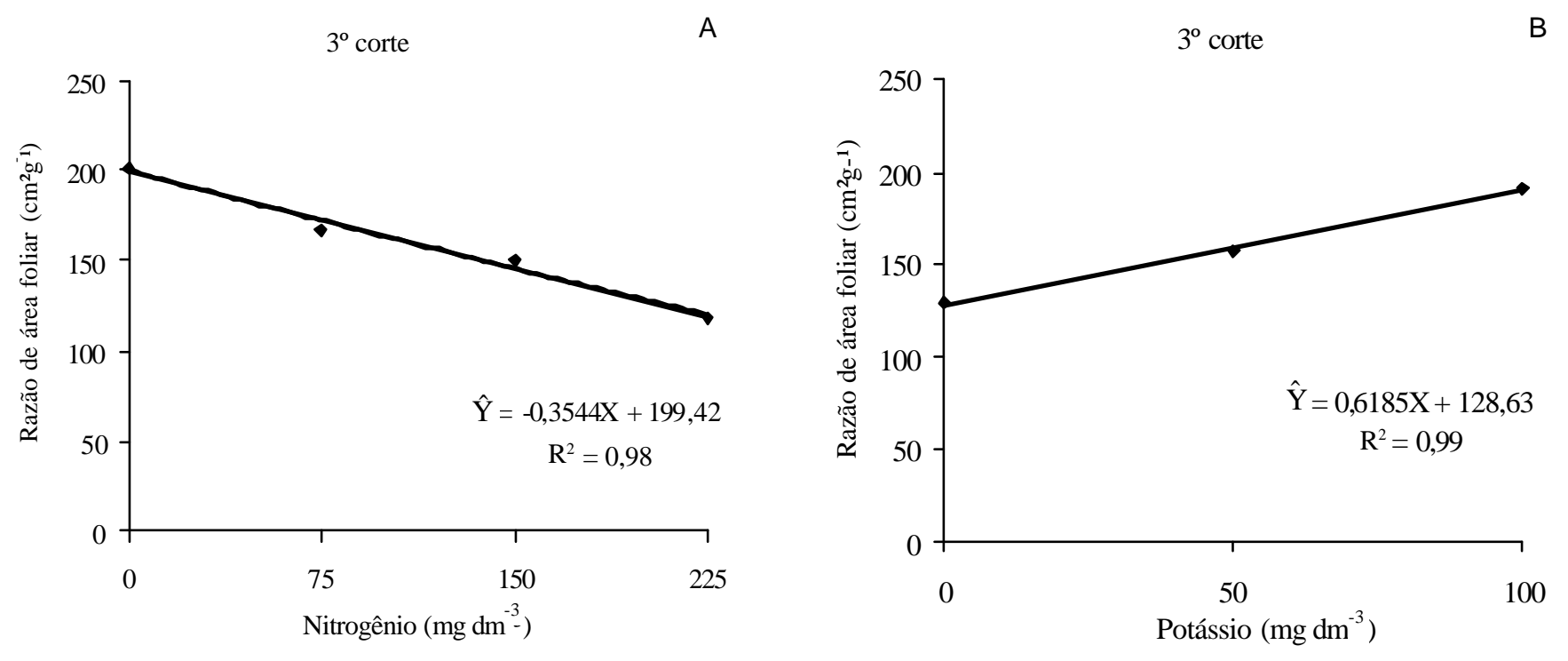

Figura 6 - Razão de área foliar $\left(\mathrm{cm}^{2} \mathrm{~g}^{-1}\right)$ em função de doses de nitrogênio (A) e doses de potássio (B) $\mathrm{mg} \mathrm{dm}^{-3}$, no $3^{\circ}$ corte.

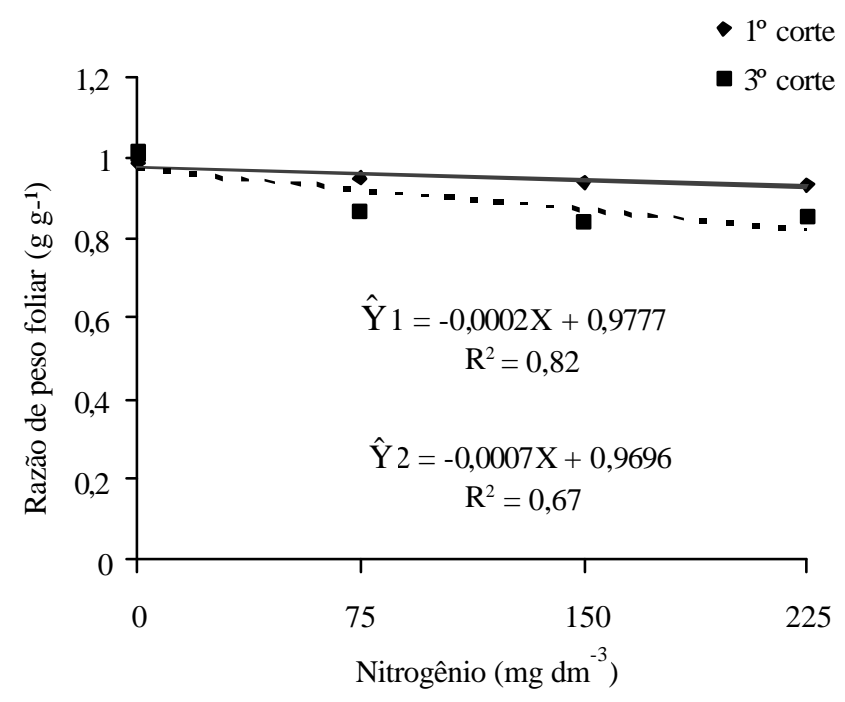

Figura 7 - Razão de peso foliar $\left(\mathrm{g} \mathrm{g}^{-1}\right)$ em função de doses de nitrogênio $\left(\mathrm{mg} \mathrm{dm}^{-3}\right)$, no 10 e 3 으 cortes.

duas situações. Analisando as equações, verificou-se que, à medida que se elevaram as doses de $\mathrm{N}$, houve redução na razão de peso foliar, nos dois cortes (Figura 7).

Para a área foliar específica (AFE), houve efeito significativo de $\mathrm{N}(\mathrm{P}=0,0439)$ e $\mathrm{K}(\mathrm{P}=0,0055)$. Pelo estudo de regressão verificou-se comportamento linear decrescente para as doses de $\mathrm{N}$ e linear crescente para as de K (Figura 8).

A ausência de significância para a RAF e AFE nos dois primeiros cortes, indica que não houve diferenças entre as doses dos nutrientes testados sobre a razão de área foliar e a área foliar específica, ou seja, nesses dois primeiros cortes, não houve grandes alterações morfológicas em razão das doses utilizadas. Provavelmente, nesse período, as plantas estariam direcionando a energia da produção de massa seca da parte aérea para a formação de seu sistema radicular, indicando variação na relação fonte/dreno. Esse fato foi confirmado pela ausência de significância da relação folha/colmo no período descrito. Estes resultados corroboram os encontrados por Pinto et al. (1994), que observaram ausência de significância para as doses de N (100 e $300 \mathrm{mg} \mathrm{kg}^{-1}$ de solo) para os capins guiné (Panicum maximum Jacq.) e setária (Setária anceps Stapf).

A correlação $\left(\mathrm{r}^{2}\right)$ RAF e AFE nesses dois períodos

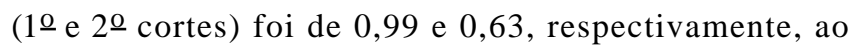
passo que a correlação RAF e RPF não foi significativa.

O comportamento linear decrescente da RPF com o aumento das doses de $\mathrm{N}$ pode ser atribuído à diminuição na relação folha/colmo (Figura 3). Assim, quanto mais a planta cresce, maior é a fração de material fotossintetizado exportada para outros órgãos que não as folhas. Como discutido anteriormente, para a relação folha/colmo, as variações neste índice refletem valor nutritivo desse cultivar. Os valores da RAF nesse período variaram de 0,987 a $0,934 \mathrm{gg}^{-1}$, sendo inferiores aos obtidos por Santos et al. (2004), para o capim-aruana (Panicum maximum, Jacq), de 1,490 a $0,275 \mathrm{~g} / \mathrm{g}$, e superiores aos valores obtidos por Oliveira et al. (2000), para o capim-tifton 85 (Cynodon sp), de 0,59 e $0,27 \mathrm{~g} / \mathrm{g}$, aos 14 e 70 dias da rebrotação. Porém, como alertou Oliveira et al. (2000), diferenças relativas nesse índice de crescimento podem decorrer da forma como é obtido. Provavelmente, os elevados valores encontrados, na maioria dos trabalhos da literatura ocorreu em razão de se utilizar somente amassa seca da parte aérea em 

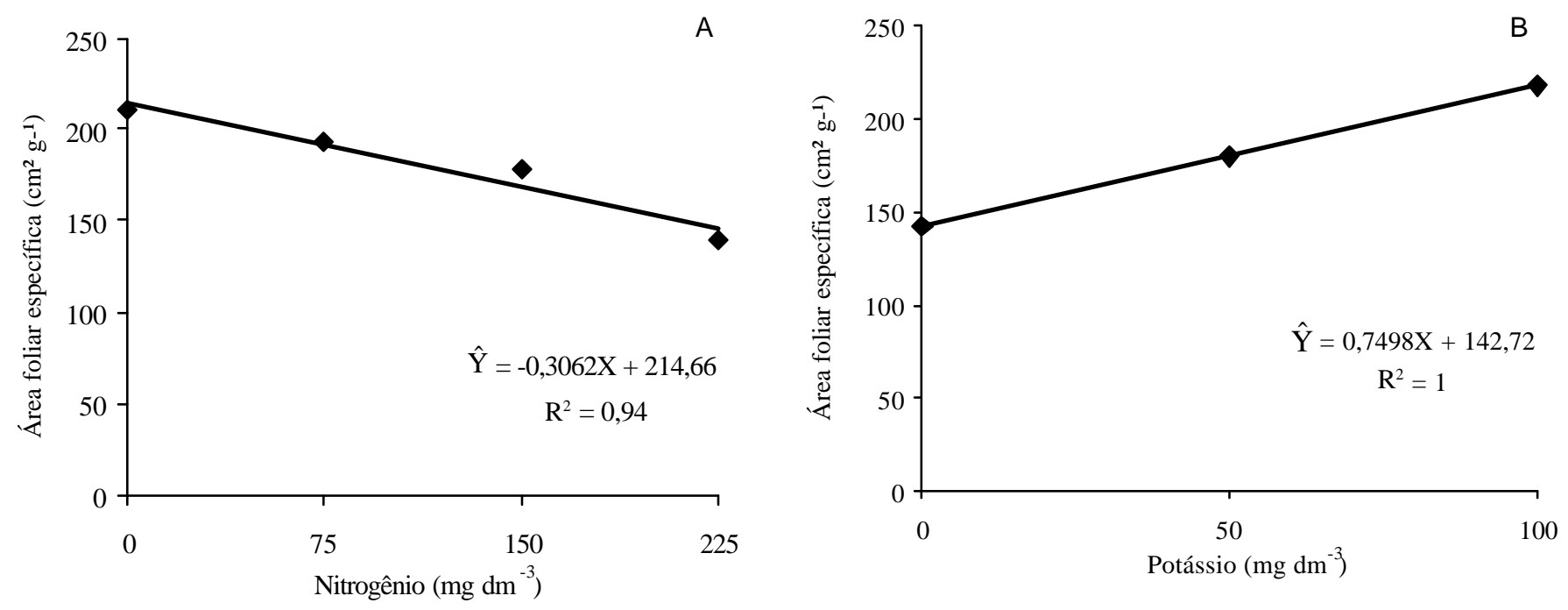

Figura 8 - Área foliar específica $\left(\mathrm{cm}^{2} \mathrm{~g}^{-1}\right)$ em função de doses de nitrogênio $(\mathrm{A})$ e doses de potássio (B) $\left(\mathrm{mg} \mathrm{dm} \mathrm{m}^{-3}\right)$, no $3^{\circ} \mathrm{corte}$.

seu cálculo. No caso deste trabalho, foi utilizada a massa seca das folhas de cada vaso pela massa seca da parte aérea de cada vaso. Ainda, segun do Benicasa (1988), as diferenças ocorrem devido ao genótipo, nesse caso deve-se ressaltar que se trata de um material novo.

A correlação RAF e RPF não foi significativa em nenhum corte, o que discorda dos resultados encontrados por Pinto et al. (1994), Oliveira et al. (2000) e Santos Jr. et al. (2005).

As respostas às doses de $\mathrm{N}$, no $3 \underline{0}$ corte, para a RAF, AFE e RPF foram linear decrescente. Com base na definição de Benicasa (1988) de que a RAF representa a unidade de área foliar usada pela planta para produzir uma unidade de peso de MS, essa redução provocada pelo aumento das doses de N na RAF é negativa para a planta, pois reflete progressiva diminuição no aparelho fotossintético em relação ao crescente peso da planta, que, por sua vez, gera maior custo da respiração de manutenção (Gomide \& Gomide, 1999).

Do mesmo modo, a AFE seguiu semelhante padrão de comportamento, reduzindo com o aumento das doses de $\mathrm{N}$ e aumentando com as doses de $\mathrm{K}$, assim, a provável explicação para a redução da estimativa dessa variável pode decorrer do crescimento ponderal das folhas relativamente à área foliar, que pode ser indício de aumento na espessura das folhas nas maiores doses de N (Benicasa, 1988; Gomide \& Gomide, 1999).

A RPF também seguiu o padrão descrito para a RAF e AFE no 30 corte, linear decrescente, com o aumento das doses de N. Como já discutido anteriormente, à medida que a planta cresce, menor é a fração retida na folha e maior a exportação para o colmo e outras partes da planta.
Analisando o conjunto de dados, verificou-se que as variações na RAF estão relacionadas às variações na AFE e RPF. A correlação RAF e AFE no 30 corte foi de 0,98 . Dessa maneira, pode-se inferir que o componente da RAF que mais interferiu nas suas variações foi a AFE, discordando dos resultados encontrados por (Pinto et al., 1994; Oliveira et al., 2000; Santos Jr. et al., 2005).

\section{Conclusões}

Há grande exportação de fotoassimilados das folhas para os colmos com o aumento das doses de nitrogênio, provocando redução na relação folha/colmo, contudo há aumento crescente da produção de folhas, refletindo na produção de massa seca total da parte aérea no Brachiaria brizantha cv. Xaraés. O potássio age de modo antagônico ao do nitrogênio sobre a AFE e RAF e pouco interferiu no rendimento deste cultivar.

\section{Agradecimento}

Ao Engenheiro Agrônomo Evandro M. de Paula da Wolf Seeds do Brasil S/A, pela cessão das sementes utilizadas neste experimento.

\section{Literatura Citada}

ALDEN, W.G.; WHITAKER, I.A. The determinants of herbage intake by grazing sheep: the inter relationship of factors influencing herbage intake and availabity. Australian Journal of Agricultural Research , v.21, n.5, p.755-766, 1970.

BENICASA, M.M.P. Análise de crescimento de plantas: noções básicas. Jaboticabal: FUNEP, 1998. 41p. 
EUCLIDES, V.P.B.; CARDOSO, E.G.; MACEDO, M.C.M. et al. Consumo voluntário de Brachiaria decumbens cv. Basilisk e Brachiaria brizantha cv. Marandu sob pastejo. Revista Brasileira de Zootecnia, v.29, n.6, p.2200-2208, 2000 (supl.2).

EMPRESA BRASILEIRA DE PESQUISA AGROPECUÁRIA EMBRAPA. Sistema brasileiro de classificação de solos. $5^{\mathrm{a}}$ aproximação. Rio de Janeiro: Centro Nacional de Pesquisa de Solos, 1999. 171p.

GOMIDE, C.A.M.; GOMIDE, J.A. Análise de crescimento de cultivares de Panicum maximum Jacq. Revista Brasileira de Zootecnia, v.28, n.4, p.675-680, 1999.

HUNT, R. Basic growth analysis: plant growth analysis for beginners. London: Unwin Hyman, 1990. 112p.

MONTEIRO, F.A.; LIMA, S.A.A.; WERNER J.C. et al. Adubação potássica em leguminosas e em capim-Colonião (Panicum maximum Jacq) adubado com níveis de nitrogênio ou consorciado com leguminosas. Boletim de Indústria Animal, v.37, p.127$148,1980$.

MONTEIRO, F.A.; RAMOS, A.K.B.; CARVALHO, D.D. et al. Cultivo de Brachiaria brizantha Stapf. cv. Marandu em solução nutritiva com omissões de macronutrientes. Scientia Agricola, v.52, n.1, p.135-141, 1995.

OLIVEIRA, J.B.; PRADO, H. Levantamento pedológico do Estado de São Paulo: quadrícula de São Carlos. II. Memorial descritivo. Campinas: Instituto Agronômico de Campinas, 1984. 188p. (Boletim Técnico, 98).

OLIVEIRA, M.A.; PEREIRA, O.G.; MARTINES y HUAMAN, C.A. et al. Características morfogênicas e estruturais do capim- bermuda Tifton 85 ( Cynodon $s p$ ) em diferentes idades de rebrota. Revista Brasileira de Zootecnia, v.29, n.6, p.1939-1948, 2000.

PINTO, J.C.; GOMIDE, J.A.; MAESTRI, M. Produção de matéria seca e relação folha/caule de gramíneas forrageiras tropicais, cultivadas em vasos, com duas doses de nitrogênio. Revista Brasileira de Zootecnia, v.23, n.3, p.313-326, 1994.

SANTOS, I.P.A.; PINTO, J.C.; MESQUITA, E.E. et al. Análise de crescimento do capim-aruana (Panicum maximum Jacq. cv. Aruana) em diferentes idades de rebrota. In: REUNIÃO ANUAL DA SOCIEDADE BRASILEIRA DE ZOOTECNIA, 41., 2004, Campo Grande. Anais... Campo Grande: Sociedade Brasileira de Zootecnia, 2004. (CD-ROM)..

SANTOS JR., J.D.G.; MONTEIRO, F.A.; MACEDO, M.C.M. et al. Componentes morfológicos do capim-Tanzânia cultivado em quatro condições de fertilidade do solo na região dos cerrados. Boletim da Indústria Animal, v.62, n.2, p.91-99, 2005.

STATISTICAL ANALYSIS SYSTEM - SAS. Propriety software release 6.11. Cary: 1996. (CD-ROM).

WERNER, J.C. Adubação de pastagens. Nova Odessa: Instituto de Zootecnia, 1986. 49 p. (Boletim Técnico, 18).

SBRISSIA, A.F.; Da SILVA, S.C. O ecossistema de pastagens e a produção animal. In: REUNIÃO ANUAL DA SOCIEDADE BRASILEIRA DE ZOOTECNIA, 38., 2001, Piracicaba. Anais... Piracicaba: Sociedade Brasileira de Zootecnia, 2001. p.731-754.

WILSON, J.R.; tMANNETJE, L. Senescence, digestibility and carbohydrate content of buffel gran and green panic leaves in swards. Australian Journal Agricultural Research, v.29, p.503-519, 1978 . 